\title{
Conversion of an ultra-wide bandgap amorphous oxide insulator to a semiconductor
}

\author{
Junghwan Kim ${ }^{1,2}$, Takumi Sekiya ${ }^{1}$, Norihiko Miyokawa ${ }^{1}$, Naoto Watanabe ${ }^{1}$, Koji Kimoto ${ }^{3}$, Keisuke Ide ${ }^{1}$, \\ Yoshitake Toda $^{2}$, Shigenori Ueda ${ }^{3,4}$, Naoki Ohashi ${ }^{2,5}$, Hidenori Hiramatsu ${ }^{1,2}$, Hideo Hosono ${ }^{1,2}$ \\ and Toshio Kamiya ${ }^{1,2}$
}

The variety of semiconductor materials has been extended in various directions, for example, to very wide bandgap materials such as oxide semiconductors as well as to amorphous semiconductors. Crystalline $\beta-\mathrm{Ga}_{2} \mathrm{O}_{3}$ is known as a transparent conducting oxide with an ultra-wide bandgap of $\sim 4.9 \mathrm{eV}$, but amorphous (a-) $\mathrm{Ga}_{2} \mathrm{O}_{x}$ is just an electrical insulator because the combination of an ultra-wide bandgap and an amorphous structure has serious difficulties in attaining electronic conduction. This paper reports semiconducting a- $\mathrm{Ga}_{2} \mathrm{O}_{x}$ thin films deposited on glass at room temperature and their applications to thin-film transistors and Schottky diodes, accomplished by suppressing the formation of charge compensation defects. The film density is the most important parameter, and the film density is increased by enhancing the film growth rate by an order of magnitude. Additionally, as opposed to the cases of conventional oxide semiconductors, an appropriately high oxygen partial pressure must be chosen for $\mathrm{a}_{-} \mathrm{Ga}_{2} \mathrm{O}_{x}$ to reduce electron traps. These considerations produce semiconducting $\mathrm{a}_{-} \mathrm{Ga}_{2} \mathrm{O}_{x}$ thin films with an electron Hall mobility of $\sim 8 \mathrm{~cm}^{2} \mathrm{~V}^{-1} \mathrm{~s}^{-1}$, a carrier density $N_{\mathrm{e}}$ of $\sim 2 \times 10^{14} \mathrm{~cm}^{-3}$ and an ultra-wide bandgap of $\sim 4.12 \mathrm{eV}$. An a- $\mathrm{Ga}_{2} \mathrm{O}_{x}$ thin-film transistor exhibited reasonable performance such as a saturation mobility of $\sim 1.5 \mathrm{~cm}^{2} \mathrm{~V}^{-1} \mathrm{~s}^{-1}$ and an on/off ratio $>10^{7}$.

NPG Asia Materials (2017) 9, e359; doi:10.1038/am.2017.20; published online 10 March 2017

\section{INTRODUCTION}

Carrier doping and consequent control of carrier density are essential requirements for semiconductors. Therefore, carrier doping to a known insulating material has been a guiding principle in developing new semiconductors. However, it is difficult to dope carriers to a wide bandgap material, as explained, for example, by the intrinsic doping limit. ${ }^{1}$ Developing new amorphous semiconductors is another area of interest because amorphous semiconductors can be fabricated even at room temperature on plastic and are applicable to flexible devices. However, obtaining electron conduction in an amorphous material is much more difficult than obtaining electron conduction in a crystalline material. Only hydrogenated amorphous silicon and amorphous oxide semiconductors (AOSs) have been utilized as active layers in practical semiconductor devices. ${ }^{2}$

Developing an ultra-wide bandgap amorphous semiconductor is very challenging and also interesting from the viewpoint of materials science. It is important also for practical applications because such materials will allow us to integrate power devices with large-size glass and flexible substrates. $\beta-\mathrm{Ga}_{2} \mathrm{O}_{3}$ is a crystalline semiconductor with an ultra-wide bandgap of $\sim 4.9 \mathrm{eV}^{3}$ and has recently been examined for applications in deep-ultraviolet devices ${ }^{4}$ and power devices. ${ }^{5}$ Although carrier doping in $\beta-\mathrm{Ga}_{2} \mathrm{O}_{3}$ has been difficult, as recently explained by theoretical calculations, ${ }^{6}$ impurity doping using $\mathrm{Sn}$ or Si has been discovered to attain electronic conduction, ${ }^{1,7}$ which has widened the range of applications of $\beta-\mathrm{Ga}_{2} \mathrm{O}_{3}$, for example, to power devices. However, although a large number of AOS materials with bandgaps of $\sim 3.0 \mathrm{eV}$, such as a-In-Ga-Zn-Sn-O, have been developed to date, ${ }^{2,8,9}$ semiconducting behavior has never been observed for amorphous $\mathrm{Ga}_{2} \mathrm{O}_{x}\left(\mathrm{a}-\mathrm{Ga}_{2} \mathrm{O}_{x}\right)$; only ionic conduction and an insulatormetal transition at a high temperature have been reported. ${ }^{10,11}$ A reason for this difficulty is that aliovalent ion doping does not work for amorphous semiconductors except for hydrogenated amorphous silicon; therefore, only metal/oxide ion off-stoichiometry and hydrogen doping would be effective doping methods in AOSs, and consequently carrier control of the conventional AOSs has been conducted mainly by controlling oxygen partial pressure during deposition and thermal annealing $\left(P_{\mathrm{O} 2}\right)$ as well as by hydrogen doping. ${ }^{12}$ Even these conventional doping methods could not produce semiconducting a- $\mathrm{Ga}_{2} \mathrm{O}_{x}$.

Here we have succeeded in fabricating semiconducting $a-\mathrm{Ga}_{2} \mathrm{O}_{x}$ thin films on glass at room temperature. A key strategy is opposite

\footnotetext{
${ }^{1}$ Laboratory for Materials and Structures, Institute of Innovative Research, Tokyo Institute of Technology, Yokohama, Japan; ${ }^{2}$ Materials Research Center for Element Strategy, Tokyo Institute of Technology, Yokohama, Japan; ${ }^{3}$ Quantum Beam Unit, National Institute for Materials Science, Ibaraki, Japan; ${ }^{4}$ Synchrotron X-ray Station at SPring-8, National Institute for Materials Science, Hyogo, Japan and ${ }^{5}$ National Institute for Materials Science, Ibaraki, Japan

Correspondence: Professor J Kim, Materials Research Center for Element Strategy, Tokyo Institute of Technology, Mailbox SE-6, 4259 Nagatsuta, Midori-ku, Yokohama 226-8503, Japan. E-mail: JH.KIM@lucid.msI.titech.ac.jp

or Professor T Kamiya, Laboratory for Materials and Structures, Institute of Innovative Research, Tokyo Institute of Technology, Mailbox R3-4, 4259 Nagatsuta, Midori-ku, Yokohama 226-8503, Japan.

E-mail: kamiya.t.aa@m.titech.ac.jp

Received 14 November 2016; revised 5 January 2017; accepted 7 January 2017
} 
a

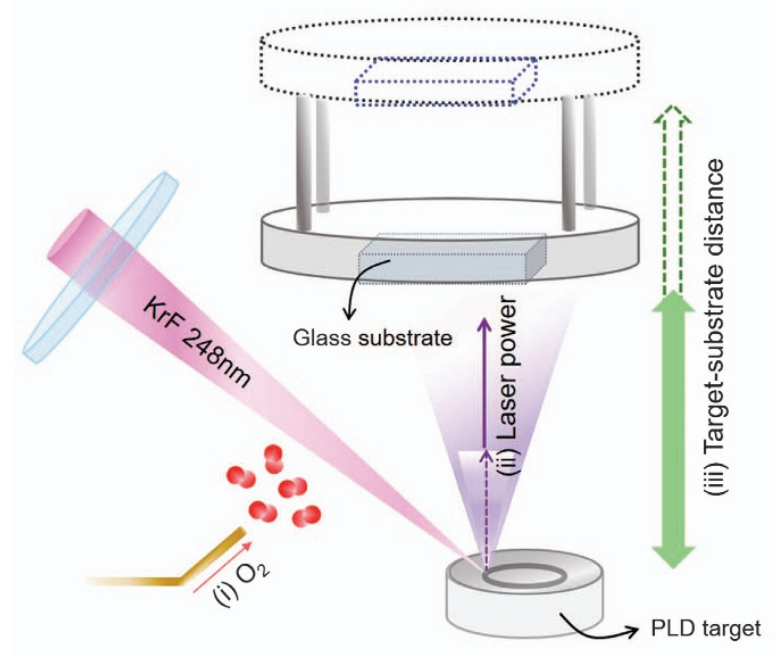

b
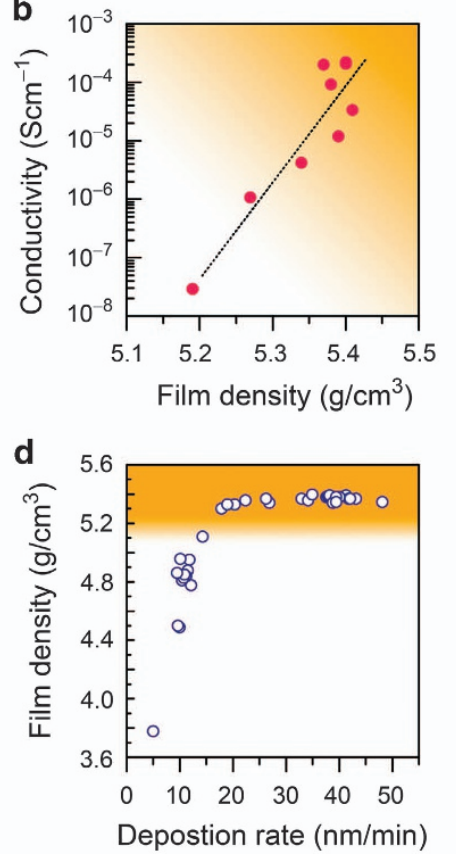

c
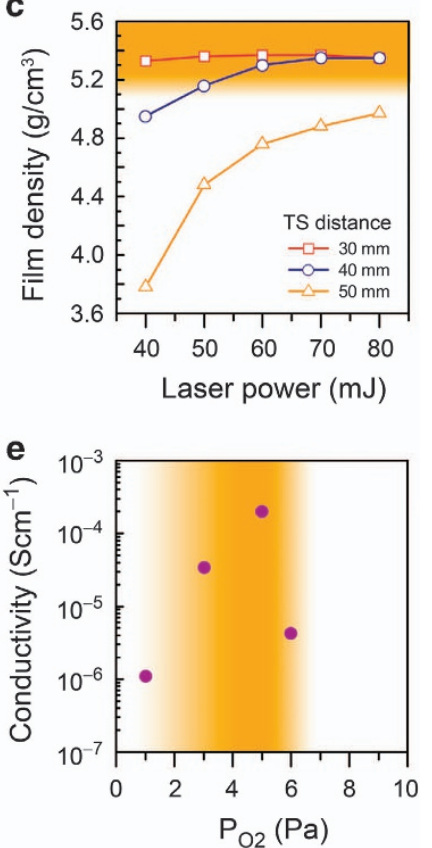

Figure 1 Relation between electronic conduction and film density. (a) Deposition parameters affecting the film structures and properties such as (i) $P_{02}$, (ii) laser power and (iii) TS distance. (b) Electrical conductivity vs film density, indicating that film densities $\geqslant 5.2 \mathrm{~g} \mathrm{~cm}^{-3}$ are required to obtain semiconducting films. (c) Film density vs laser power and TS distance. (d) Replot of panel (b) with respect to deposition rate, giving a single universal curve between deposition rate and film density. (e) $P_{02}$ dependence of conductivity, showing that too low $(<1 \mathrm{~Pa})$ and too high $P_{02}(>6 \mathrm{~Pa})$ produced insulating films only.

to the strategy for conventional oxide semiconductors where a lower $P_{\mathrm{O} 2}$ is chosen to obtain a higher electron density and better conductivity. Another important key is to increase the film growth rate to obtain a higher film density so that formation of electron traps is suppressed. Furthermore, incorporation of weakly bonded or excess oxygen should also be suppressed. Thus semiconducting a- $\mathrm{Ga}_{2} \mathrm{O}_{x}$ thin films were obtained with an electron Hall mobility of $\sim 8 \mathrm{~cm}^{2} \mathrm{~V}^{-1} \mathrm{~s}^{-1}$, a carrier density of $\sim 2 \times 10^{14} \mathrm{~cm}^{-3}$ and a bandgap of $\sim 4.12 \mathrm{eV}$, which produced operating semiconductor devices including thin-film transistors (TFTs) and Schottky diodes.

\section{MATERIALS AND METHODS}

$\mathrm{a}-\mathrm{Ga}_{2} \mathrm{O}_{x}$ films were fabricated by pulsed laser deposition (PLD) using a $\mathrm{KrF}$ excimer laser (wavelength: $248 \mathrm{~nm}$ ) in an $\mathrm{O}_{2}$ gas flow on silica glass substrates at room temperature. The back pressure for PLD was $\sim 2 \times 10^{-6} \mathrm{~Pa}$. We synthesized polycrystalline targets of $\beta-\mathrm{Ga}_{2} \mathrm{O}_{3}, \quad\left(\mathrm{Ga}_{0.35} \mathrm{Zn}_{0.65}\right)_{2} \mathrm{O}_{x}$ and $\left(\mathrm{Ga}_{0.7} \mathrm{Zn}_{0.3}\right)_{2} \mathrm{O}_{x}$ from powdered reagents of $\mathrm{ZnO}$ (purity 99.999\%) and $\mathrm{Ga}_{2} \mathrm{O}_{3}$ (purity $99.99 \%$ ) by sintering at $1400{ }^{\circ} \mathrm{C}$ for $5 \mathrm{~h}$ in air. $P_{\mathrm{O} 2}$ during deposition and laser power were varied from 0 to $10 \mathrm{~Pa}$ and from 30 to $80 \mathrm{~mJ}$, respectively. Some films were subjected to postdeposition thermal annealing at $T_{\mathrm{a}}=200-600{ }^{\circ} \mathrm{C}$ in vacuum, dry $\mathrm{O}_{2}$ and $\mathrm{H}_{2}$ gas flows.

Film structures and thicknesses were characterized and determined by highresolution transmission electron microscopy, X-ray diffraction and grazingincidence X-ray reflectivity spectroscopy, which confirmed that all of the films examined in this study were amorphous (see X-ray diffraction, high-resolution transmission electron microscopy and grazing-incidence X-ray reflectivity in Supplementary Figures S1-S3, respectively). Optical bandgap values $\left(E_{\mathrm{g}}\right)$ were estimated by Tauc' plots for the amorphous films.

Electrical properties were measured by the Hall effect with the van der Pauw configuration. Desorption of the film constituents and impurity-related species was measured by thermal desorption spectroscopy (TDS). For the TDS measurement, $\sim 140$-nm-thick a- $\mathrm{Ga}_{2} \mathrm{O}_{\mathrm{x}}$ films were deposited under different deposition conditions. Then the samples were taken out to the air once from the PLD deposition chamber and then introduced into the TDS measurement chamber. The back pressure of the TDS chamber was $\sim 2 \times 10^{-7} \mathrm{~Pa}$.

Chemical composition (Ga:O ratio) was determined using an electron-probe microanalyzer equipped with a field-emission-type electron gun and a wavelength dispersive X-ray detector. Hard X-ray photoemission spectroscopy (HAXPES) measurements at room temperature were performed using the BL15XU undulator beamline (the excitation X-ray energy: $h \nu=5953.4 \mathrm{eV}$ ) ${ }^{13,14}$ of SPring-8. The binding energy was calibrated with the $E_{\mathrm{F}}$ of an evaporated $\mathrm{Au}$ thin film, and the total energy resolution was set to $240 \mathrm{meV}$, which was confirmed by the Fermi cutoff of the Au film. The energy levels of the conduction band minimum (CBM, $\left.E_{\mathrm{CBM}}\right)$ and the valence band maximum (VBM, $\left.E_{\mathrm{VBM}}\right)$ from the vacuum level $\left(E_{\mathrm{VAC}}\right)\left(E_{\mathrm{VAC}}-E_{\mathrm{CBM}}\right.$ and $E_{\mathrm{VAC}}-E_{\mathrm{VBM}}$ are electron affinity, $\chi$, and ionization potential, $I_{\mathrm{p}}$, respectively) were measured by ultraviolet photoemission spectroscopy (UPS) (excited by He I and II light sources). To prepare chemically pure surfaces for the UPS measurements, Ar ion sputtering was conducted for $1 \mathrm{~h}$ at an acceleration voltage of $1 \mathrm{kV}$. Work function was determined from the cutoff energy of secondary electrons, and $I_{\mathrm{p}}$ was estimated by combining $E_{\mathrm{VAC}}$ and the measured $E_{\mathrm{VBM}}$ (see Supplementary Figure S4). $\chi$ was speculated using the measured optical bandgap by $\chi=I_{\mathrm{p}}+E_{\mathrm{g}}$.

Bottom-gate, top-contact TFTs were fabricated using semiconducting a- $\mathrm{Ga}_{2} \mathrm{O}_{x}$ channels on $\mathrm{SiO}_{2} / \mathrm{n}^{+}-\mathrm{Si}$ substrates (see Figure $5 \mathrm{a}$ for the device structure). The a- $\mathrm{Ga}_{2} \mathrm{O}_{x}$ layers were deposited at room temperature, followed by thermal annealing at $200^{\circ} \mathrm{C}$ under vacuum. Finally, aluminum source/drain contacts were deposited by thermal evaporation. A- $\mathrm{Ga}_{2} \mathrm{O}_{x} / \mathrm{Pt}$ Schottky diodes were fabricated on $\mathrm{Pt} /$ silica glass substrates, finished by evaporating aluminum top Ohmic contacts (Figure $5 \mathrm{c}$ ).

\section{RESULTS AND DISCUSSION}

Controlling factor to obtain semiconducting $a-\mathrm{Ga}_{2} \mathrm{O}_{\mathrm{x}}$

In the beginning of this work, we employed film growth conditions that were similar to device-quality a-In-Ga-Zn-O (a-IGZO) for 

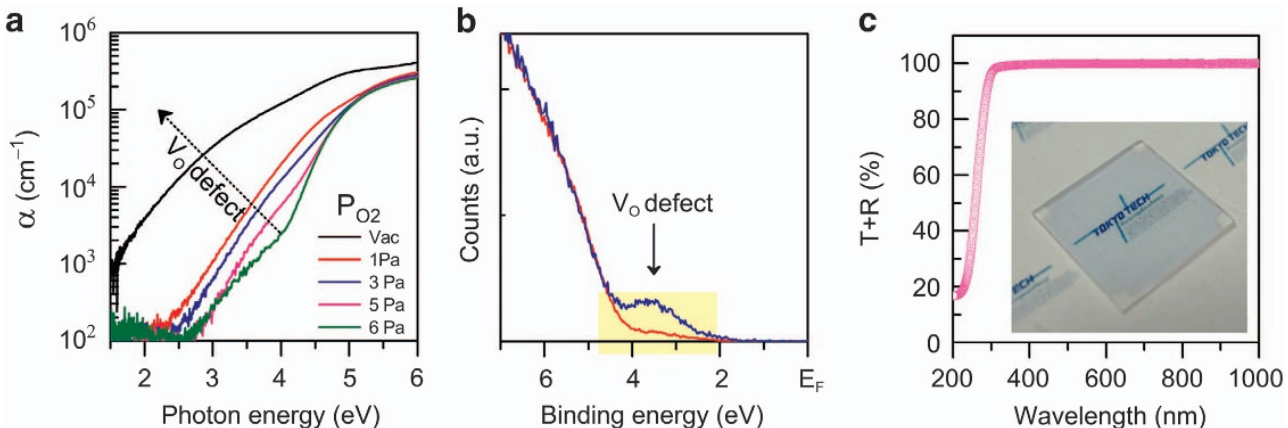

Figure 2 Subgap defects in a-Ga $\mathrm{O}_{X^{*}}$ (a) Optical absorption spectra as a function of $P_{02}$ from 0 to $6 \mathrm{~Pa}$. (b) HAXPES spectra around the bandgap region for conducting and insulating films deposited at $P_{02}=6 \mathrm{~Pa}$ (the red curve) and $1 \mathrm{~Pa}$ (the black curve), respectively. The binding energy is measured from the Fermi level, and the VBMs are located at $\sim 4.1 \mathrm{eV}$. (c) Transmittance+reflectance spectra and photo of the conducting a-Ga $\mathrm{O}_{x}$ film of $\sim 120 \mathrm{~nm}$ thickness.
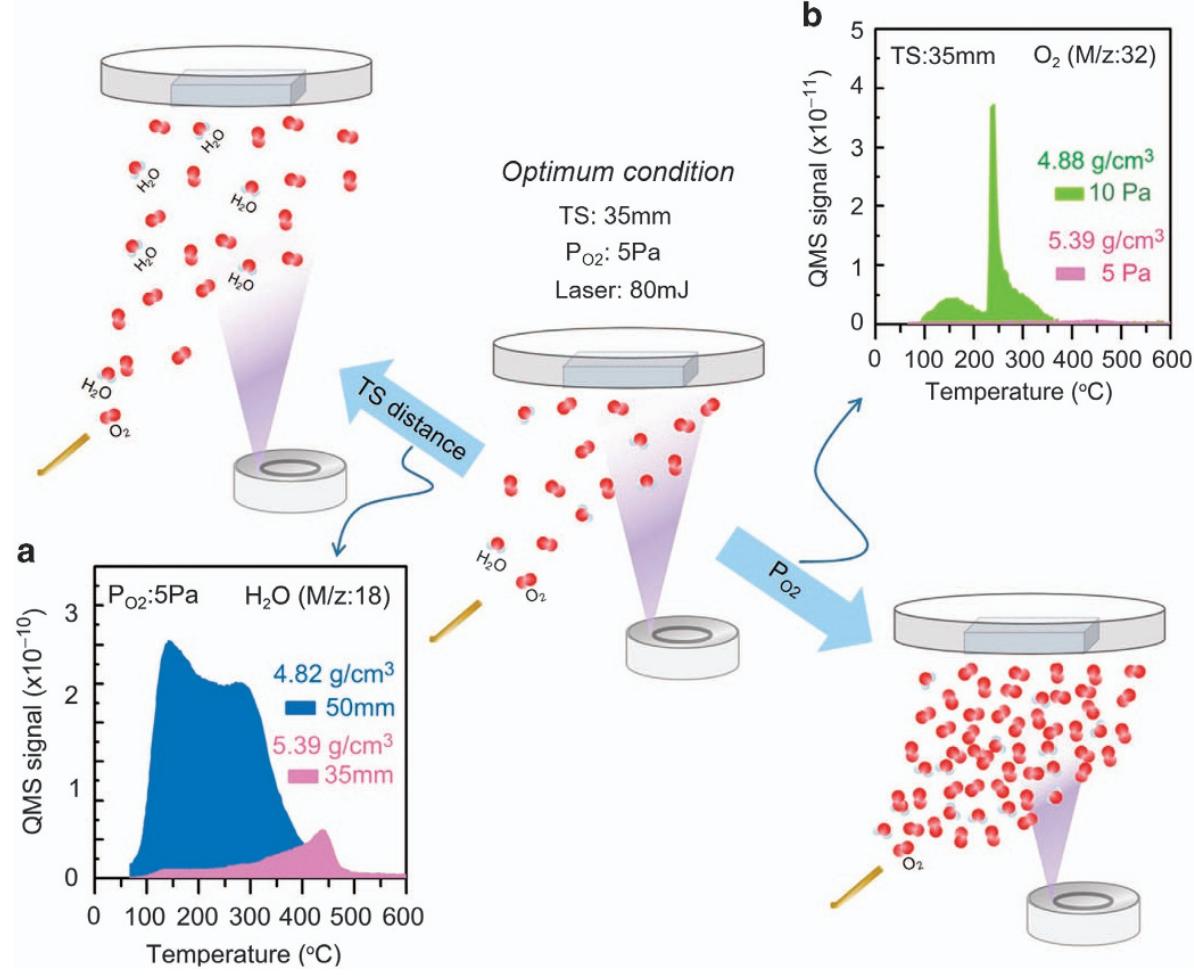

Figure 3 Schematic illustration of the effects of deposition parameters (TS distance and $P_{02}$ ) on incorporation of impurity species. (a, b) TDS spectra of (a) $\mathrm{H}_{2} \mathrm{O}$ (TS distances are $50 \mathrm{~mm}$ for blue and $35 \mathrm{~mm}$ for purple) and (b) $\mathrm{O}_{2}$ ( $P_{02}$ are $10 \mathrm{~Pa}$ for green and $5 \mathrm{~Pa}$ for purple). The TS distance of $35 \mathrm{~mm}$ and the $P_{02}=5 \mathrm{~Pa}$ are the optimum conditions and produced the high-density semiconducting a- $\mathrm{Ga}_{2} \mathrm{O}_{x}$ film.

PLD (that is, $P_{\mathrm{O} 2}$ of $1-5 \mathrm{~Pa}$, target-substrate (TS) distance of $50 \mathrm{~mm}$ and laser power of $50 \mathrm{~mJ}$ ) because these a-IGZO films produce good TFTs and have low defect densities even when deposited at room temperature on glass. ${ }^{15,16}$ However, all of the $\mathrm{a}-\mathrm{Ga}_{2} \mathrm{O}_{x}$ films thus fabricated were insulators with electrical conductivities below the measurement limit of our apparatus $\left(<10^{-8} \mathrm{~S} \mathrm{~cm}^{-1}\right)$, although we had examined wider deposition conditions from $P_{\mathrm{O} 2}=0 \mathrm{~Pa}$ and performed several postdeposition treatments such as thermal annealing in vacuum, $\mathrm{O}_{2}$, and $\mathrm{H}_{2}$ because these are standard procedures to dope electrons onto oxide semiconductors.

By investigating further wider deposition conditions including the TS distance and the laser power, we finally found the deposition conditions to obtain electron conduction as shown in Figure 1. Electrical conductivities were obtained only if the film density was $>5.2 \mathrm{~g} \mathrm{~cm}^{-3}$ (Figures $1 \mathrm{~b}$ and $\mathrm{c}$ ), where the electrical conductivity increased exponentially with the increase in the film density. Figure $1 c$, in which the films exhibiting electrical conductivity are shown by the orange shaded region, shows that the TS distance and laser power are not the essential controlling factors because the smallest TS distance of $30 \mathrm{~mm}$ produced conducting films independent of the laser power, but the larger TS distances failed to attain conductivity, particularly for low laser power. Replotting these data with respect to the deposition rate (Figure 1d) gives a single universal curve, indicating that the film density is the essential controlling factor. The deposition rates for device-quality a-IGZO 


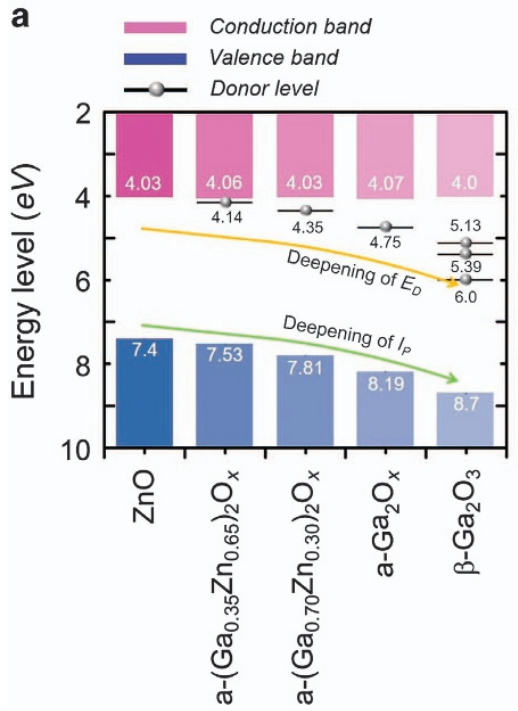

b

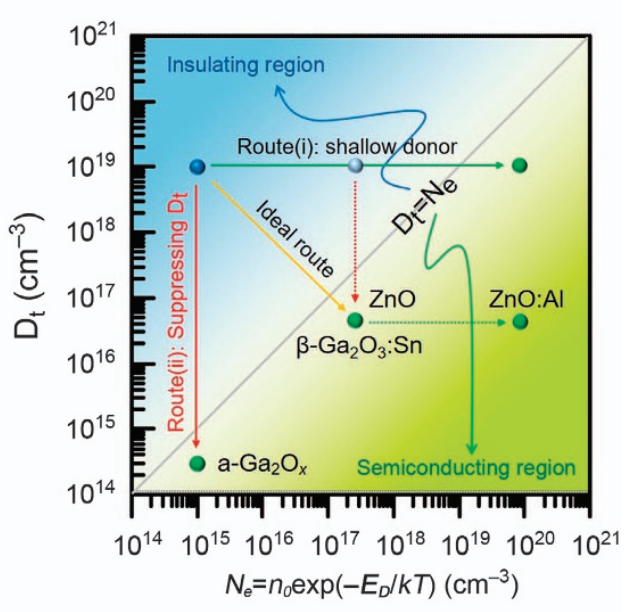

Figure 4 (a) Band alignment diagram of a- $\left(\mathrm{Ga}_{1-y} \mathrm{Zn}_{y}\right)_{2} \mathrm{O}_{x}$ in comparison with crystalline $\mathrm{ZnO}$ built from $E_{\mathrm{g}}$ and UPS results in Supplementary Figure S4 of the supporting information. The values for $\mathrm{ZnO}$ and $\beta-\mathrm{Ga}_{2} \mathrm{O}_{3}$ are taken from $\mathrm{Klein}^{23}$ and Mohamed and Schottky ${ }^{24}$, respectively. The $E_{\mathrm{D}}$ value for $\beta$-Ga $\mathrm{O}_{3}$ is taken from Varley et al. ${ }^{6} E_{\mathrm{VBM}}$ (ionization potential, $I_{\mathrm{P}}$ ) is shown by the top edges of the blue bars and $E_{\mathrm{CBM}}$ (electron affinity, $\chi$ ) by the bottom edges of the purple bars. $E_{\mathrm{D}}$ levels are also shown by the horizontal bars with spheres. (b) The schematic diagram shows routes to convert an insulator to a semiconductor.

films are $\sim 5 \mathrm{~nm} \mathrm{~min}^{-1}$, and the deposition rates required for semiconducting a- $\mathrm{Ga}_{2} \mathrm{O}_{x}$ films are larger by one to several orders of magnitude.

$P_{\mathrm{O} 2}$ is also an essential controlling parameter to attain conducting films. We should, however, emphasize that the optimum $P_{\mathrm{O} 2}$ obtained for $\mathrm{a}-\mathrm{Ga}_{2} \mathrm{O}_{x}$ is very different from the value for conventional oxide semiconductors for which a lower $P_{\mathrm{O} 2}$ is required to obtain a higher electronic conduction and a higher free electron density. That is, low $P_{\mathrm{O} 2}$ including zero (that is, in vacuum) produced insulating a- $\mathrm{Ga}_{2} \mathrm{O}_{x}$ films only, and the best conductivity of $\sim 2 \times 10^{-4} \mathrm{~S} \mathrm{~cm}^{-1}$ was obtained at a rather high $P_{\mathrm{O} 2}=5 \mathrm{~Pa}$. This value can be explained from the subgap defects observed in optical absorption spectra (Figure 2a) and HAXPES spectra around the bandgap region (Figure $2 \mathrm{~b}$ ). Similar to previous reports, ${ }^{10,17}$ the low $P_{\mathrm{O} 2}$ films seem to have small apparent $E_{\mathrm{g}}$ due to subgap absorption, but the actual $E_{\mathrm{g}}$ is estimated to be $4.12 \mathrm{eV}$ from the Tauc' plot of the $P_{\mathrm{O} 2}=6 \mathrm{~Pa}$ film because it has the smallest subgap absorption. Strong subgap absorption extends from $E_{\mathrm{g}}=4.12$ to $0.5 \mathrm{eV}$ for the $P_{\mathrm{O} 2}=0$ film. The subgap absorption originates from the subgap defects just above the VBM (near-VBM states) as seen in the HAXPES spectra in Figure $2 \mathrm{~b}$, where the VBM level is estimated to be $\sim 4.1 \mathrm{eV}$ from the Fermi level $\left(E_{\mathrm{F}}\right)$ by extrapolating the straight VB tail to zero. The film deposited at a low $P_{\mathrm{O} 2}=1 \mathrm{~Pa}$ (the film density of $5.27 \mathrm{~g} \mathrm{~cm}^{-3}$ ) shows high-density peakshape near-VBM states (denoted ' $V_{\mathrm{O}}$ defect' for the black curve), while the film deposited at the optimum $P_{\mathrm{O} 2}=6 \mathrm{~Pa}\left(5.39 \mathrm{~g} \mathrm{~cm}^{-3}\right)$ has much smaller near-VBM states (the red curve). These results are similar to previously reported a-IGZO cases and explain that a low $P_{\mathrm{O} 2}$ condition produces electron traps, probably due to oxygen deficiency with free space (void) structures. ${ }^{18}$ This result explains the $P_{\mathrm{O} 2}$ vs conductivity result in Figure 1e because lower $P_{\mathrm{O} 2}$ may generate free electrons due to oxygen deficiency as usual for oxide semiconductors, while it also produces the near-VBM defects and these defects trap all the generated electrons, leading to the stronger charge compensation at lower $P_{\mathrm{O} 2}$ and consequently to the insulating films.
The next question is why the film deposition rate determines the film density as seen in Figure 1d. TDS spectra in Figures $3 a$ and $b$ show that the film density is altered largely by the TS distance and $P_{\mathrm{O} 2}$. The low-density film deposited at a large TS distance of $50 \mathrm{~mm}$ exhibited high-density desorption of $\mathrm{H}_{2} \mathrm{O}$ molecules even from the very low temperature of $\sim 80^{\circ} \mathrm{C}$, implying that lower density films incorporate more impurities such as $\mathrm{H}_{2} \mathrm{O}, \mathrm{OH}$ and $\mathrm{H}$-related molecules. This result suggests that the low density would come from incorporation of residual $\mathrm{H}_{2} \mathrm{O}$ and $\mathrm{H}$-related molecules in the PLD chamber because a lower growth rate requires a longer deposition time and incorporates more impurity from the deposition atmosphere into the growing film as illustrated in Figure 3. There is another important factor to determine the film density; a higher deposition rate condition would produce deposition precursors with higher kinetic energies, which enhances structural relaxation in the growing surface region and assists in forming a denser structure.

Figure 1e shows that the optimum $P_{\mathrm{O} 2}$ were 5-6 Pa, but the conductivity dropped sharply by further increasing $P_{\mathrm{O} 2}$, and no conducting film was obtained at $>6 \mathrm{~Pa}$. The $\mathrm{O}_{2}$ TDS spectra in Figure $3 \mathrm{~b}$ show that the film deposited at the optimum condition of $P_{\mathrm{O} 2}=5 \mathrm{~Pa}$ did not show $\mathrm{O}_{2}$ desorption up to $350^{\circ} \mathrm{C}$ (note that this film is of high density), while the film deposited at a high $P_{\mathrm{O} 2}=10 \mathrm{~Pa}$ (a low-density film) exhibited a large amount of $\mathrm{O}_{2}$ desorption even from the low temperature of $80^{\circ} \mathrm{C}$. A similar result is observed in a-IGZO films fabricated under strong oxidation conditions, and similar low-temperature $\mathrm{O}_{2}$ desorption is attributed to weakly bonded oxygen that forms an electron trap. ${ }^{19-21}$ Similar to the a-IGZO case, the insulating behavior of the high $P_{\mathrm{O} 2}$ a- $\mathrm{Ga}_{2} \mathrm{O}_{x}$ films can be explained by the charge compensation due to the electron traps originating from the weakly bonded oxygen.

\section{Electronic structure of $\mathrm{a}-\mathrm{Ga}_{2} \mathrm{O}_{\mathrm{x}}$}

Next, we investigated the electronic structure of a- $\mathrm{Ga}_{2} \mathrm{O}_{x}$. To systematically investigate the variation of electronic structure, we compared the electronic structure of a- $\mathrm{Ga}_{2} \mathrm{O}_{x}$ with the electronic structure of its 
a
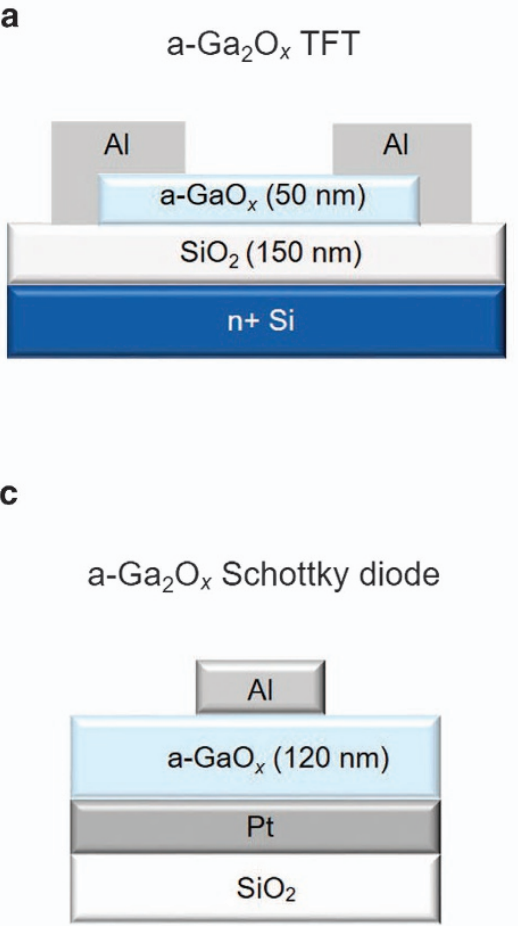
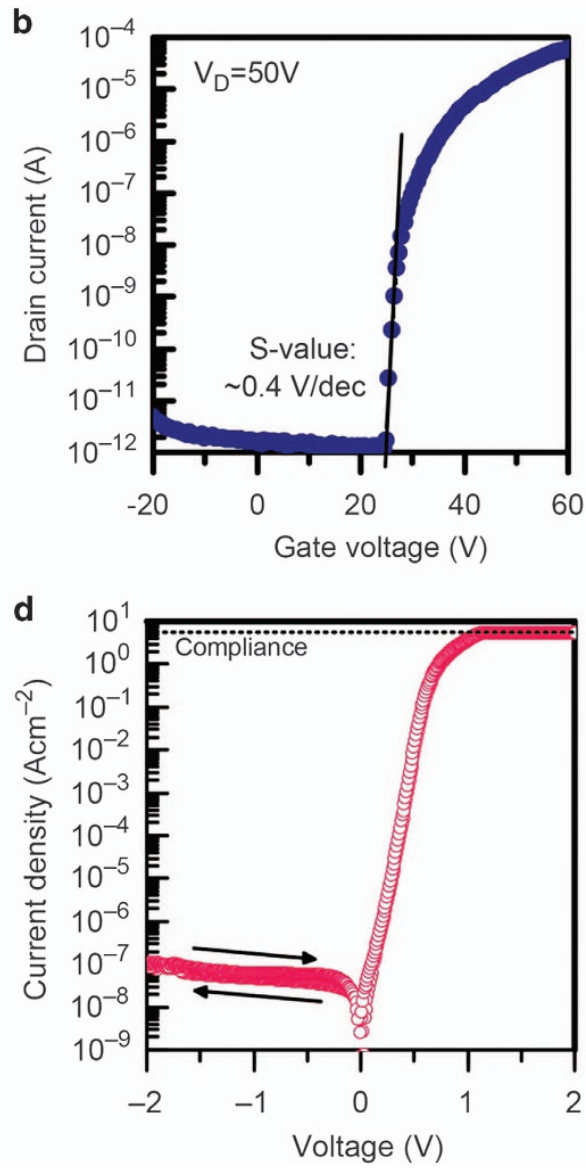

Figure 5 a- $\mathrm{Ga}_{2} \mathrm{O}_{x}$ devices. (a) TFT structure and (b) transfer characteristic. (c) Schottly diode structure and (d) current-voltage characteristic.

solid-solution system a- $\left(\mathrm{Ga}_{1-y} \mathrm{Zn}_{y}\right)_{2} \mathrm{O}_{x} \quad(y=0, \quad 0.30, \quad 0.65)$. Their electrical properties, the temperature dependence of electrical conductivity $\left(\sigma_{\mathrm{e}}\right)$, electron Hall mobility $\left(\mu_{\mathrm{e}}\right)$ and free electron density $\left(n_{\mathrm{e}}\right)$ are summarized in Supplementary Figure S5 and Supplementary Table S1, which substantiated that all of the films were n-type semiconductors and that their donor levels measured from the CBM deepen with the decreasing $\mathrm{Zn}$ content from $E_{\mathrm{CBM}}-E_{\mathrm{D}}=0.08$ to 0.32 and to $0.68 \mathrm{eV}$ for a- $\left(\mathrm{Ga}_{0.35} \mathrm{Zn}_{0.65}\right)_{2} \mathrm{O}_{x}$ to $\mathrm{a}-\left(\mathrm{Ga}_{0.70} \mathrm{Zn}_{0.30}\right)_{2} \mathrm{O}_{x}$ and to $\mathrm{a}-\mathrm{Ga}_{2} \mathrm{O}_{x}$, respectively. The total donor densities $n_{0}$ were also estimated from the equation $n_{\mathrm{e}}=n_{0} \exp \left(-\left(E_{\mathrm{CBM}}-E_{\mathrm{D}}\right) /\left(k_{\mathrm{B}} T\right)\right)$, providing $n_{0}=1.0 \times 10^{18}, \quad 1.5 \times 10^{18}$ and $7.5 \times 10^{19} \mathrm{~cm}^{-3}$ for $\mathrm{a}-\left(\mathrm{Ga}_{0.35} \mathrm{Zn}_{0.65}\right)_{2} \mathrm{O}_{x}$, a- $\left(\mathrm{Ga}_{0.70} \mathrm{Zn}_{0.30}\right)_{2} \mathrm{O}_{x}$ and $\mathrm{a}-\mathrm{Ga}_{2} \mathrm{O}_{x}$, respectively. These densities indicate that although $n_{0}$ is the largest for $\mathrm{a}-\mathrm{Ga}_{2} \mathrm{O}_{x}$, $n_{\mathrm{e}}$ is limited due to the deep donor level, $E_{\mathrm{CBM}}-E_{\mathrm{D}}$. All of the a- $\left(\mathrm{Ga}_{1-y} \mathrm{Zn}_{y}\right) \mathrm{O}_{x}$ films exhibited rather large electron mobility for amorphous semiconductors, $6-8 \mathrm{~cm}^{2} \mathrm{~V}^{-1} \mathrm{~s}^{-1}$ at room temperature, similar to a-IGZO. ${ }^{15,16}$ This result substantiates that the low value for $\sigma_{\mathrm{e}}$ of a- $\mathrm{Ga}_{2} \mathrm{O}_{x}$ of $\sim 2 \times 10^{-4} \mathrm{~S} \mathrm{~cm}^{-1}$ at most originates from the low $n_{\mathrm{e}}$, not from $\mu_{\mathrm{e}}$. This origin would be reasonable because both a-IGZO and $a-\mathrm{GaO}_{x}$ have similar CBM structures made mainly of spherical metal $s$ orbitals, which can form a highly dispersed conduction band with small electron effective masses even in a disordered amorphous structure. ${ }^{22}$

The $E_{\mathrm{g}}$ values, which were determined from Tauc' plots (Supplementary Figure S4d), were 4.12, 3.78 and $3.47 \mathrm{eV}$ for a- $\left(\mathrm{Ga}_{0.35} \mathrm{Zn}_{0.65}\right)_{2} \mathrm{O}_{x}$, a- $\left(\mathrm{Ga}_{0.70} \mathrm{Zn}_{0.30}\right)_{2} \mathrm{O}_{x}$ and $\mathrm{a}-\mathrm{Ga}_{2} \mathrm{O}_{x}$, respectively, and the ionization potential $\left(I_{\mathrm{P}}=E_{\mathrm{VBM}}\right)$ values were obtained by UPS measurements (Supplementary Figure S2). Consequently, the band alignment diagram is built as shown in Figure 4a. The diagram shows that $E_{\mathrm{VBM}}$ deepens as the $\mathrm{Zn}$ content decreases while $E_{\mathrm{CBM}}$ remains almost unchanged, indicating that the difference in $E_{\mathrm{g}}$ comes mostly from the deepening of $E_{\mathrm{VBM}}$. This result would be unexpected because one may expect that $E_{\mathrm{VBM}}$ values of oxide semiconductors are similar because their VBM levels are mainly made of the common chemical states, $\mathrm{O} 2 \mathrm{p}-\mathrm{O} 2 \mathrm{p}$ antibonding states, and consequently, it would be natural to expect that the $\mathrm{Ga}^{3+} 4 \mathrm{~s}$ level, which constitutes the CBM in $\mathrm{Ga}_{2} \mathrm{O}_{x}$, lies at a shallower energy than $\mathrm{Zn}^{2+} 4 \mathrm{~s}$ as speculated from the difference in $E_{\mathrm{g}}$. However, this result indicates that the energy levels of the unoccupied $s$ orbitals in $\mathrm{Ga}^{3+}$ and $\mathrm{Zn}^{2+}$ are similar, while $E_{\mathrm{g}}$ is determined mainly by $E_{\mathrm{VBM}}$. A similar result is also reported for crystalline $\beta-\mathrm{Ga}_{2} \mathrm{O}_{3} .{ }^{24}$ This trend is explained by an $\mathrm{O} 2 \mathrm{p}-\mathrm{Zn} \quad 3 \mathrm{~d}$ interaction as reported for II-VI semiconductors; ${ }^{25}$ that is, the $\mathrm{Zn} 3 \mathrm{~d}$ level is shallower than $\mathrm{Ga} 3 \mathrm{~d}$ and has a larger antibonding coupling with $\mathrm{O} 2 \mathrm{p}$ states, which raises $E_{\mathrm{VBM}}$ as the $\mathrm{Zn}$ content increases. The doping limit in many $n$-type oxides is determined by their $E_{\text {CBM }}$ measured from the vacuum level. ${ }^{26,27}$ Thus $\beta-\mathrm{Ga}_{2} \mathrm{O}_{3}$ and $\mathrm{a}-\mathrm{Ga}_{2} \mathrm{O}_{\mathrm{x}}$ can be doped to n-type because their $E_{\mathrm{CBM}}$ values are close to that of $\mathrm{ZnO}$ and within this doping limit. We also see an interesting relation between $E_{\mathrm{D}}$ and $E_{\mathrm{VBM}}$ in Figure $4 \mathrm{a}$. In the a- $\left(\mathrm{Ga}_{1-\gamma} \mathrm{Zn}_{y}\right) \mathrm{O}_{x}$ case, the $E_{\mathrm{D}}$ level deepens as the $\mathrm{Zn}$ content increases (that is, $E_{\mathrm{CBM}}-E_{\mathrm{D}}=0.08$, 0.32 and $0.68 \mathrm{eV}$ for $y=0.65,0.30$ and 0 , respectively) and appears to have a stronger correlation with $E_{\mathrm{VBM}}$ than with $E_{\mathrm{CBM}}$; that is, the $E_{\mathrm{D}}-E_{\mathrm{VBM}}$ are almost the same at $7.45,7.49$ and $7.13 \mathrm{eV}$. 
Here we discuss why the semiconductor conversion of $\mathrm{a}-\mathrm{Ga}_{2} \mathrm{O}_{x}$ was so difficult. As schematically shown in Figure 4b, good transparent conducting oxides such as $\mathrm{Al}$-doped $\mathrm{ZnO}(\mathrm{ZnO}: \mathrm{Al})$ have a high free electron concentration, for example, at $>10^{20} \mathrm{~cm}^{-3}$, generated from a shallow donor level of $\mathrm{Al}_{\mathrm{Zn}}$, while the electron trap density $\left(D_{t}\right)$ would be negligible compared to the free electron concentration. However, the blue region in Figure $4 \mathrm{~b}$ has highdensity electron traps and/or low-density free electrons generated from the donors, producing electrical insulators. Ultra-wide bandgap amorphous materials can attain electronic conduction only with difficulty because the ultra-wide gap leads to low $N_{\mathrm{e}}$ and the amorphous structure leads to high $D_{\text {t }}$. As seen in Figure $4 \mathrm{a}$, the donor level in a- $\mathrm{Ga}_{2} \mathrm{O}_{x}$ is very deep at $0.68 \mathrm{eV}$ and gives $N_{\mathrm{e}}$ as small as $10^{15} \mathrm{~cm}^{-3}$; therefore, very small $D_{\mathrm{t}}>10^{15} \mathrm{~cm}^{-3}$ are critical, and only insulating a- $\mathrm{Ga}_{2} \mathrm{O}_{x}$ films had been obtained to date. Consequently, as shown by 'Route(ii)', the semiconducting $\mathrm{a}-\mathrm{Ga}_{2} \mathrm{O}_{x}$ films here are obtained by suppressing $D_{\mathrm{t}}$.

\section{Applications to semiconductor devices}

The potential of the semiconducting a- $\mathrm{Ga}_{2} \mathrm{O}_{x}$ films was demonstrated by fabricating TFTs (Figure 5a) and Schottky diodes (Figure 5c). The $\mathrm{a}-\mathrm{Ga}_{2} \mathrm{O}_{x}$ TFT exhibited a reasonable performance such as a saturation mobility of $\sim 1.5 \mathrm{~cm}^{2} \mathrm{~V}^{-1} \mathrm{~s}^{-1}$, an on/off ratio of $>10^{7}$ and a subthreshold swing voltage of $\sim 0.4 \mathrm{~V} \mathrm{dec}^{-1}$ (Figure $5 \mathrm{~b}$ ). The a- $\mathrm{Ga}_{2} \mathrm{O}_{\mathrm{x}} / \mathrm{Pt}$ Schottky diode also shows a good currentvoltage characteristic with a very high on/off ratio $\left(>10^{9}\right)$ with a negligible hysteresis (Figure 5d). Although the a- $\mathrm{Ga}_{2} \mathrm{O}_{x} / \mathrm{Pt}$ Schottky junction was reported by Aoki, ${ }^{11}$ it operated via ion conduction in $\mathrm{a}-\mathrm{Ga}_{2} \mathrm{O}_{x}$.

\section{CONCLUSIONS}

Semiconducting a- $\mathrm{Ga}_{2} \mathrm{O}_{x}$ thin films with a bandgap of $4.12 \mathrm{eV}$ were successfully fabricated on glass at room temperature, and the electronic structure was clarified in comparison with its $\mathrm{Zn}$ solid solutions. The keys to obtaining electronic conduction in $\mathrm{a}-\mathrm{Ga}_{2} \mathrm{O}_{x}$ are (i) a high film density and (ii) an appropriately high $P_{\mathrm{O} 2}$ to suppress formation of electron traps. As the donor level is very deep, $0.68 \mathrm{eV}$ from $E_{\mathrm{CBM}}$, for $\mathrm{a}-\mathrm{Ga}_{2} \mathrm{O}_{x}$, the free electron density is still low, $2 \times 10^{14} \mathrm{~cm}^{-3}$ at best, although the total donor density is rather high, $7.5 \times 10^{19} \mathrm{~cm}^{-3}$. The formation of a trace amount of electron traps at an order of $10^{14} \mathrm{~cm}^{-3}$ is therefore critical to fully compensate for the generated free carriers, making a sharp contrast with conventional oxide semiconductors. Those conventional oxides have shallow donor levels and high-density free electrons, and therefore, the effect of charge-compensating electron traps is invisible and low $P_{\mathrm{O} 2}$ deposition conditions effectively produce high carrier density, high conductivity films. The present result shows that this strategy for conventional oxide semiconductors should be reconsidered for developing new semiconductor materials that have very wide bandgaps, deep donor/acceptor levels and/or other extreme conditions/requirements. Seeking a deposition/annealing condition/ method to suppress charge compensating defects should also be considered.

This discovery, that is, the importance of controlling charge compensation, will lead to developing further new semiconductors as well as to improving carrier transport properties and device performance of known oxide semiconductors in which generating high-density carriers or obtaining high-performance devices is difficult, such as p-type oxide semiconductors.

\section{CONFLICT OF INTEREST}

The authors declare no conflict of interest.

\section{ACKNOWLEDGEMENTS}

This work was supported by the Ministry of Education, Culture, Sports, Science and Technology (MEXT) through the Element Strategy Initiative to Form Core Research Center. JK and KI were also supported by the Japan Society for the Promotion of Science (JSPS) through a Grant-in-Aid for Research Activity Start-up Grant Nos. 16H06795 and 15H06207, respectively. H Hiramatsu was also supported by Support for Tokyotech Advanced Research (STAR).

Author contributions: TK and H Hosono supervised the project. JK, TS, NM and NW fabricated and characterized the samples with support by KI and $\mathrm{H}$ Hiramatsu. KK performed transmission electron microscope observations. YT, SU and NO performed HAXPES measurements and their analyses. JK wrote the manuscript with contributions mainly from TK, KI and $\mathrm{H}$ Hiramatsu and comments from H Hosono, KK and SU. All authors have given their approval for the final version of the manuscript.

1 Walukiewicz, W. Intrinsic limitations to the doping of wide-gap semiconductors. Physica B 123, 302-303 (2001).

2 Nomura, K, Ohta, H., Takagi, A., Kamiya, T., Hirano, M. \& Hosono, H. Room-temperature fabrication of transparent flexible thin-film transistors using amorphous oxide semiconductors. Nature 432, 488-492 (2004).

3 Orita, M., Ohta, H., Hirano, M. \& Hosono, H. Deep-ultraviolet transparent conductive $\beta-\mathrm{Ga}_{2} \mathrm{O}_{3}$ thin films. Appl. Phys. Lett. 77, 4166 (2000).

4 Matsuzaki, K., Yanagi, H., Kamiya, T., Hiramatsu, H., Nomura, K., Hirano, M. \& Hosono, H. Field-induced current modulation in epitaxial film of deep-ultraviolet transparent oxide semiconductor $\mathrm{Ga}_{2} \mathrm{O}_{3}$. Appl. Phys. Lett. 88, 092106 (2006).

5 Higashiwaki, M., Sasaki, K., Kuramata, A., Masui, T. \& Yamakoshi, S. Gallium oxide $\left(\mathrm{Ga}_{2} \mathrm{O}_{3}\right)$ metal-semiconductor field-effect transistors on single-crystal $\beta-\mathrm{Ga}_{2} \mathrm{O}_{3}$ (010) substrates. Appl. Phys. Lett. 100, 013504 (2012).

6 Varley, J., Weber, J., Janotti, A. \& Van de Walle, C. Oxygen vacancies and donor impurities in $\beta-\mathrm{Ga}_{2} \mathrm{O}_{3}$. Appl. Phys. Lett. 97, 142106 (2010).

7 Villora, E., Shimamura, K., Yoshikawa, Y., Ujiie, T. \& Aoki, K. Electrical conductivity and carrier concentration control in $\beta-\mathrm{Ga}_{2} \mathrm{O}_{3}$ by $\mathrm{Si}$ doping. Appl. Phys. Lett. 92, 202120 (2008).

8 Chiang, H., Wager, J., Hoffman, R., Jeong, J. \& Keszler, D. High mobility transparent thin-film transistors with amorphous zinc tin oxide channel layer. Appl. Phys. Lett. 86, 013503 (2005).

9 Ogo, Y., Nomura, K., Yanagi, H., Kamiya, T., Hirano, M. \& Hosono, H. Amorphous SnGa-Zn-O channel thin-film transistors. Phys. Stat. Sol. (A) 205, 1920-1924 (2008).

10 Nagarajan, L. A chemically driven insulator-metal transition in non-stoichiometric and amorphous gallium oxide. Nat. Mater. 7, 391-398 (2008).

11 Aoki, Y. Bulk mixed ion electron conduction in amorphous gallium oxide causes memristive behavior. Nat. Commun. 5, 3473 (2014)

12 Kamiya, T., Nomura, K. \& Hosono, H. Present status of amorphous In-Ga-Zn-O thin-film transistors. Sci. Technol. Adv. Mater. 11, 044305 (2010).

13 Ueda, S., Katsuya, Y., Tanaka, M., Yoshikawa, H., Yamashita, Y., Ishimaru, S., Matsushita, Y. \& Kobayashi, K. Present status of the NIMS contract beamline BL15XU at SPring-8. AlP Conf. Proc. 1234, 403 (2010).

14 Ueda, S. Application of hard X-ray photoelectron spectroscopy to electronic structure measurements for various functional materials. J. Electron. Spectrosc. Relat. Phenom. 190, 235-241 (2013).

15 Suresh, A., Wellenius, P., Dhawa, A. \& Muth, J. Room temperature pulsed laser deposited indium gallium zinc oxide channel based transparent thin film transistors. Appl. Phys. Lett. 90, 123512 (2007).

16 Nomura, K., Takagi, A., Kamiya, T., Ohta, H., Hirano, M. \& Hosono, H. Amorphous oxide semiconductors for high-performance flexible thin-film transistors. Jpn J. Appl. Phys. 45, 4303 (2006).

17 Heinemann, M., Berry, J., Teeter, G., Unold, T. \& Ginley, D. Oxygen deficiency and $\mathrm{Sn}$ doping of amorphous $\mathrm{Ga}_{2} \mathrm{O}_{3}$. Appl. Phys. Lett. 108, 022107 (2016).

18 Nomura, K., Kamiya, T., Yanagi, H., Ikenaga, E., Yang, K., Kobayashi, K., Hirano, M. \& Hosono, H. Subgap states in transparent amorphous oxide semiconductor, In-Ga-Zn0 , observed by bulk sensitive x-ray photoelectron spectroscopy. Appl. Phys. Lett. 92, 202117 (2008).

19 Ide, K., Kikuchi, Y., Nomura, K., Kimura, M., Kamiya, T. \& Hosono, H. Effects of excess oxygen on operation characteristics of amorphous In-Ga-Zn-O thin-film transistors. Appl. Phys. Lett. 99, 093507 (2011).

20 Orui, T., Herms, J., Hanyu, Y., Ueda, S., Watanabe, K., Sakaguchi, I., Ohashi, N., Hiramatsu, H., Kumomi, H., Hosono, H. \& Kamiya, T. Charge compensation by excess oxygen in amorphous In-Ga-Zn-O films deposited by pulsed laser deposition. J. Displ. Technol. 11, 518-522 (2015).

21 Kim, J., Miyokawa, N., Ide, K., Toda, Y., Hiramatsu, H., Hosono, H. \& Kamiya, T. Room-temperature fabrication of light-emitting thin films based on amorphous oxide semiconductor. AIP Adv. 6, 015106 (2016). 
22 Hosono, H. Ionic amorphous oxide semiconductors: material design, carrier transport, and device application. J. Non-Cryst. Solids 352, 851-858 (2006).

23 Klein, A. Transparent conducting oxides for photovoltaics: manipulation of fermi level, work function and energy band alignment. Materials 3, 4892-4914 (2010).

24 Mohamed, M. Schottky barrier height of $\mathrm{Au}$ on the transparent semiconducting oxide $\beta-\mathrm{Ga}_{2} \mathrm{O}_{3}$. Appl. Phys. Lett. 101, 132106 (2012).

25 Wei, S. \& Zunger, A. Role of metal d states in II-VI semiconductors. Phys. Rev. B 37 , 8958 (1988).

26 Van de Walle, C. G. \& Neugebauer, J. Universal alignment of hydrogen levels in semiconductors, insulators and solutions. Nature 423, 626-628 (2003).

27 Robertson, J. \& Clark, S. J. Limits to doping in oxides. Phys. Rev. B 83, 075205 (2011). (c) (i) This work is licensed under a Creative Commons Attribution 4.0 International License. The images or other third party material in this article are included in the article's Creative Commons license, unless indicated otherwise in the credit line; if the material is not included under the Creative Commons license, users will need to obtain permission from the license holder to reproduce the material. To view a copy of this license, visit http://creativecommons.org/licenses/by/4.0/

(C) The Author(s) 2017

Supplementary Information accompanies the paper on the NPG Asia Materials website (http://www.nature.com/am) 